\title{
Detection and correction of incomplete duplicate 24-hour urine collections - theory and practical evidence
}

\author{
Raymond W Wulkan*1, Martin van der Horst ${ }^{2}$ \\ ${ }^{1}$ Clinical Chemistry Laboratory, Maasstad Hospital, Rotterdam, The Netherlands \\ ${ }^{2}$ Clinical Chemistry Laboratory, Treant Health Care Group, Scheper Hospital Location, Emmen, The Netherlands \\ *Corresponding author:WulkanR@maasstadziekenhuis.nl
}

\begin{abstract}
Introduction: The intraindividual variability in urinary creatinine excretion is notoriously large. The aims of this study were to investigate the variability of duplicate consecutive 24-hour urinary creatinine excretions in patients and to develop a model for the detection and correction of discrepant creatinine excretions.

Materials and methods: A group of 270 patients ( 82 men and 188 women) were included in the study. We collected the following data: urinary 24-hour volumes (volumetric/gravimetric) and urinary creatinine concentrations (Jaffé/enzymatic) on both collection days. We performed specific calculations to detect discrepant creatinine excretions.

Results: In 60 patients (22\%) discrepant collections were found. Among the remaining 78\%, 22\% of the patients collected very accurately (almost identical urinary creatinine excretions). In this subgroup the volume ratios and the creatinine concentration ratios behave inversely as in a dilution curve. A theoretical model and six collection scenarios were developed to detect, interpret and correct discrepant collections. Practical examples are given to illustrate the use of the model in successful correction of creatinine and other analytes for under- or overcollection.

Conclusions: We conclude that missed or overcollected urine volumes are the largest source of variation in creatinine excretion. Discrepancies in consecutive duplicate 24-hour creatinine excretions can be detected and corrected with specific calculations by means of the presented model. The effectiveness of these corrections is demonstrated with examples from daily practice. These calculations can be easily automated.
\end{abstract}

Keywords: urine specimen collection; creatinine/urine; patient compliance

\section{Introduction}

The creatinine excretion in a 24-hour urine collection is a measure of muscular mass and renal function (1). This excretion may serve as an early indicator of sarcopenia $(2,3)$. Accuracy of urine collection is therefore important, however the control of the completeness of collection is difficult. The methods to correct for incomplete collection, such as $p$ aminobenzoic acid excretion, the use of the creatinine index or the estimated creatinine excretion are far from ideal, as has been shown recently (4). In spite of the many reports of the high intraindividual variability of the 24 -hour creatinine excre- tion, healthy, well instructed individuals may well collect with high precision, achieving a within person variation coefficient of $3.6 \%$ (5). The aims of this study were to investigate the variability of duplicate consecutive 24-hour urinary creatinine excretions in patients and to develop a model for the detection and correction of discrepant creatinine excretions.

Part of this work has been published previously in an observational study in Dutch language (6). The patient data, the development of detection limits 
and the findings from the literature presented here are the same as in the original publication. For clarity we have not omitted these parts, because this would disturb the line of reasoning too much. The new elements in the current article are the development of the mathematical model, the various scenarios derived from the model, the curved dependence of the creatinine ratio on the volume ratio, the detailed examples of aberrant collections and finally the equations that may be used for correction, as well as examples of corrections.

\section{Materials and methods}

\section{Subjects}

Adult outpatients of the Maasstad Hospital (Rotterdam, The Netherlands) and the Spijkenisse Medical Center (Spijkenisse, The Netherlands) collected duplicate, consecutive 24-hour urines for routine analysis (i.e. over 48 hours). Duplicate consecutive urine collections were analysed in order to eliminate the long term influences of changes in muscle mass, renal function or medication. The patient group consisted of 82 men (aged 21-85 years; median 61) and 188 women (aged 22-88 years; median 63) with hypertension, obesity or fractures. The urines were collected for the investigation of Cushing syndrome, pheochromocytoma, carcinoid tumor, porphyria, or osteoporosis/ multiple myeloma in patients with fractures.

\section{Methods}

Patients were instructed both verbally and in writing to empty their bladder early in the morning, to write down the time of day and to start the collection until the same time the next morning, to add the first portion of urine to the first collection and to write down again the time of day. When the collection time was deviating by less than one hour, the volume was corrected to the 1440 minutes of a complete day, otherwise collections were rejected. Urinary creatinine was measured by a Jaffé method (Dimension VISTA, Siemens Healthcare Diagnostics Inc., Tarrytown, USA) or by an enzymatic method (Cobas 6000, Roche Diagnostics GmbH, Mannheim, Germany). Both methods were cali- brated to the assigned reference value of the external quality control material of the Dutch national external quality control organization. The urinary volume was either measured with a measuring cylinder or by weighing. The between day differences in creatinine excretion and volume were calculated by subtracting the values of the second day from those of the first day. The percentage difference in volume was determined by dividing the difference by the mean volume of both days. We chose this approach because it can not be known beforehand which of both collections is incorrect. All data were anonymised and were collected prospectively. The reference ranges for the excretion of creatinine are $8.0-22.0 \mathrm{mmol} / 24 \mathrm{~h}$ for men and 6.0-17.0 $\mathrm{mmol} / 24 \mathrm{~h}$ for women. These reference ranges originate from the PREVEND study. This is a study with 2627 Dutch subjects living in the general population (7). The reference range for the 24hour volume is $1000-3500 \mathrm{~mL} / 24 \mathrm{~h}(8)$.

\section{Statistical analysis}

Standard statistical calculations were performed in Microsoft Excel 2010 (Microsoft, Redmond, USA). The curve fitting was done in GraphPad Prism, version 7.0a (GraphPad Software, San Diego, USA).

\section{Theoretical model}

We describe a model for the situation of accurate collections in order to allow the systematical detection and correction of inaccurate collections. When both collections are correct, the creatinine excretions in $1440 \mathrm{~min}$ ( $\mathrm{mmol} / 24 \mathrm{~h})\left(\mathrm{Cr}_{24}\right)$ should be equal: $\mathrm{Cr}_{24-1}=\mathrm{Cr}_{24-2}$ (where 1 and 2 represent the designation of the collection day) or $\mathrm{V}_{1} \times \mathrm{c}_{1}=$ $V_{2} \times c_{2}$ (where $c$ represents the creatinine concentration, and $V$ the urine volume in $1440 \mathrm{~min}$ $(\mathrm{mL} / 24 \mathrm{~h}))$. This can be rewritten as $\left(\mathrm{V}_{1} / \mathrm{V}_{2}\right) \times\left(\mathrm{c}_{1} / \mathrm{c}_{2}\right)$ $=1$. The mathematical product of $V_{1} / V_{2}$ and $c_{1} / c_{2}$ (R) will be abbreviated as $R=1$; thus $c_{1} / c_{2}=1 /\left(V_{1} /\right.$ $V_{2}$ ). When the volume ratio $V_{1} / V_{2}$ is plotted on the $X$-axis and the creatinine concentration ratio $c_{1} / c_{2}$ on the $Y$ axis, the following hyperbolic curve is obtained: $y=1 / x$. In order to improve our understanding of the diverse presentations we used the model to describe six possible scenarios of incorrect collections. 


\section{The six scenarios}

For every point of the line $y=1 / x$ the $R$ factor is equal to unity. This is the situation of perfect collections $\left(R=\left(V_{1} / V_{2}\right) \times\left(c_{1} / c_{2}\right)=1\right)$. However, when $R$ deviates from unity, the collections are less perfect. $R$ can be larger or smaller than unity.

In case of $R>1$, the creatinine excretion on the first day is larger than on the second day $\left(V_{1} c_{1}>V_{2} C_{2}\right)$. If we accept that $c_{1}$ and $c_{2}$ (and their ratio) are correct, there can only be three causes for $R>1: V_{1}$ is too large, $V_{2}$ too small, or a combination of both (Figure 1).

1. The situation of an isolated too large $V_{1}$ is rare. This occurs when the patient does not empty the bladder before collecting and adds this portion to $\mathrm{V}_{1}$. The patient is located in sector $\mathrm{N}$ or A dependent on the volume of the missed portion (5\% of the patients are located in sector A) (Figure 1).

2. In case of an isolated grossly too low $\mathrm{V}_{2}$. The patient is located in sector B (1\% of the patients) (Figure 1). In this situation the lowest volume $\left(V_{2}\right)$ may be seen in combination with the lowest creatinine $\left(c_{2}\right)$. This is an illogical combination, because volume and concentration behave inversely. The real $V_{2}$ must have been higher and some volume has been missed. There might have been a spill of the second collection.

3. In situations of a too large $V_{1}$ with a too small $V_{2}$. The patient is located in sector $A$ (Figure 1). The patient may not have emptied the bladder before collecting $V_{1}$ and also mistakenly disposed the last portion of $\mathrm{V}_{2}$. Note that the volume difference doubles because both collections are affected. These double mistakes are less likely to occur.

In case $R<1$, the creatinine excretion on the first day is smaller than on the second day $\left(V_{1} c_{1}\right.$ $<\mathrm{V}_{2} \mathrm{C}_{2}$ ). If we accept that $\mathrm{c}_{1}$ and $\mathrm{c}_{2}$ (and their ratio) are correct, there can only be three causes for $R<1$ : $V_{1}$ is too small, $V_{2}$ too large or a combination of both (Figure 1).

4. An isolated grossly too low $V_{1}$. It is rare $(<1 \%$ of the patients). In this situation the patient is located in sector F (Figure 1). In this situation the lowest volume $\left(\mathrm{V}_{1}\right)$ may be seen in combination with almost equal creatinine concentra- tions. There might have been a spill of the first collection.

5. The situation of an isolated too large $V_{2}$. It is rare $(<1 \%$ of the patients). The patient has extended the second collection beyond the second day. The patient is located in $\mathrm{F}$ (Figure 1).

6. In case of a too small $V_{1}$ with a too large $V_{2}$. The patient is located in sector $E$ (Figure 1). This is the most frequently found situation ( $10 \%$ of the patients). It occurs when the patient mistakenly adds the last portion of the first day to the second collection on the morning of the second day. The displaced volume is roughly the content of a urine bladder $(250-400 \mathrm{~mL})$; this diminishes $V_{1}$ but adds to $V_{2}$ so the difference in volume is doubled.

The patient may be found in sector C or G ( $2 \%$ of the patients in either sector) when there is a large difference in water excretion, but only a small difference in creatinine excretion (Figure 1). The ratio $\mathrm{V}_{1} / \mathrm{V}_{2}$ is then large (in $\mathrm{C}$ ) or small (in $\mathrm{G}$ ) and therefore $\mathrm{R}$ may be larger or smaller than unity, respectively. The patient has collected correctly, but

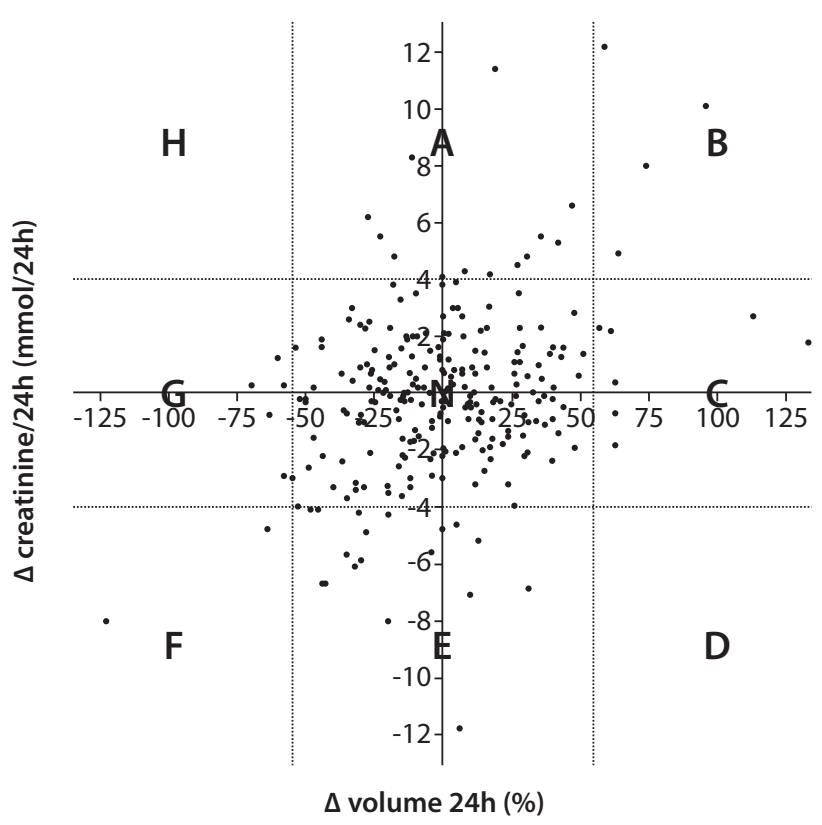

Figure 1. Scatter plot of the data of the patient group. The relative differences in 24-hour volume (X-axis) and the absolute differences in 24-hour creatinine excretion (Y-axis) are shown. The dotted detection limits divide the figure into nine sectors indicated in alphabetical order. These symbols are used in the discussion of the collection scenarios. 
there is a large difference in water excretion. We remarkably did not find any of our patients in sector $\mathrm{D}$ or $\mathrm{H}$. Both sectors represent illogical combinations of measurements. For instance, in sector $D$ this would be $V_{1}>V_{2}$ in combination with $c_{1}>c_{2}$. When a patient is nevertheless found in sector $D$ or $\mathrm{H}$ this may have been the result of a clerical error in the transcription of the volume.

\section{Results}

The characteristics of the patient group are represented in Table 1. In short, they covered a broad range of age, volume and creatinine excretion.

\section{Choice of detection limits}

Twenty-three of the 270 patients had a large (arbitrarily $>5.0 \mathrm{mmol} / 24 \mathrm{~h}$ ) absolute difference between both creatinine excretions and were removed as outliers, leaving 247 patients. From this population a standard deviation in creatinine excretions of $2.0 \mathrm{mmol} / 24 \mathrm{~h}$ was calculated, and a $95 \%$ confidence interval of $\pm 4.0 \mathrm{mmol} / 24 \mathrm{~h}$. We used this interval as a definition of acceptable collections, which also means that values outside this interval are considered as having an unacceptable difference between both collections. We adopted limits from the difference of 24-hour volume as \pm $55 \%$ from the literature (9). In our group of patients
$60 / 270$ (22\%) were found outside the detection limits, indicating unacceptable collection errors.

\section{Experimental evidence of the theoretical model}

We selected from our group of 270 patients those with an absolute value of the creatinine excretion difference in the first and second day $\left(\left|\Delta \mathrm{Cr}_{24}\right|\right)<0.5$ $\mathrm{mmol} / 24 \mathrm{~h}$ (near to perfect collections). Sixty patients (22\%) fulfilled this criterion. From this subgroup we plotted the volume ratio $\left(V_{1} / V_{2}\right)$ against the concentration ratio $\left(c_{1} / c_{2}\right)$ and obtained the line $y=1.0 / x^{1.02}$ with a correlation coefficient of 0.990 (Figure 2).

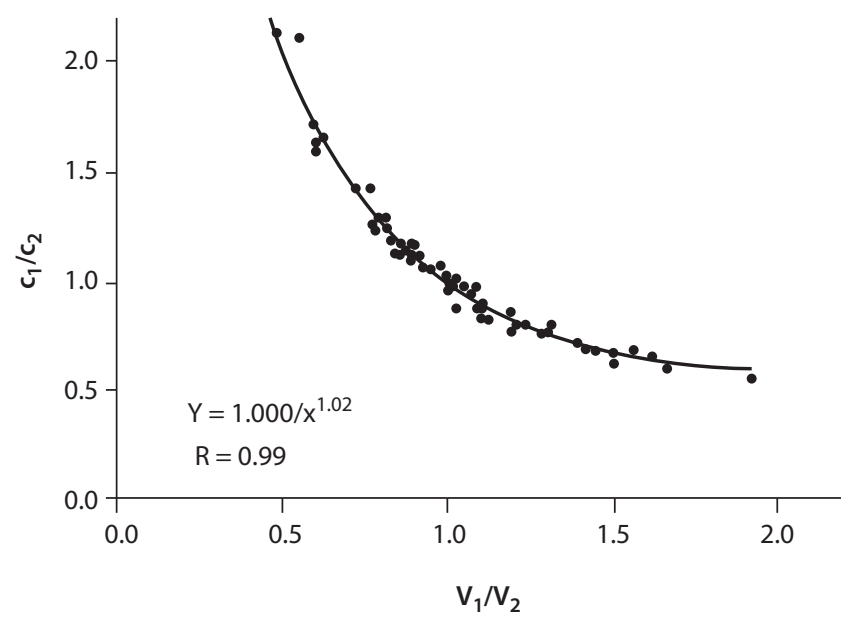

FIGURE 2. Volume ratio against the creatinine concentration ratio plotted for the 60 patients who collected accurately.

TABLE 1. Demographic and measurement data of the patient group

\begin{tabular}{|c|c|c|c|c|c|c|}
\hline & \multicolumn{6}{|c|}{$\mathbf{N}=\mathbf{2 7 0}$} \\
\hline & \multicolumn{3}{|c|}{ Male ( $\mathbf{N}=82)$} & \multicolumn{3}{|c|}{ Female ( $N=188)$} \\
\hline & $\mathbf{N}$ & Mean (min-max) & SD & $\mathbf{N}$ & Mean (min-max) & SD \\
\hline Age (years) & 79 & $61(21-85)$ & 14 & 178 & $63(22-88)$ & 15 \\
\hline Weight (kg) & 38 & $94.5(70-148)$ & 17.5 & 79 & $78.3(34-162)$ & 21 \\
\hline Length (cm) & 34 & $176.6(110-192)$ & 13.2 & 62 & $165.6(147-188)$ & 8.1 \\
\hline BMI $\left(\mathrm{kg} / \mathrm{m}^{2}\right)$ & 32 & $29.8(23.6-52.4)$ & 6.1 & 63 & $29.4(16.7-58.1)$ & 8.3 \\
\hline $\mathrm{Cr}$ in plasma $(\mu \mathrm{mol} / \mathrm{L})$ & 17 & $96(60-143)$ & 26.6 & 52 & $68(46-124)$ & 13.3 \\
\hline $\mathrm{Cr}$ in urine $(\mathrm{mmol} / \mathrm{L})$ & 82 & $9.4(3.0-20.2)$ & 4.1 & 188 & $5.8(1.5-14.2)$ & 2.7 \\
\hline $\mathrm{Cr}_{24}(\mathrm{mmol} / 24 \mathrm{u})$ & 82 & $14.4(6.2-26.8)$ & 4.2 & 188 & $8.6(1.8-16.1)$ & 2.9 \\
\hline Volume $(\mathrm{mL})$ & 82 & 1767 (514-3888) & 651 & 188 & 1737 (468-4090) & 673 \\
\hline
\end{tabular}

Age is presented as median (range). $\mathrm{Cr}$ - creatinine concentration. $\mathrm{Cr}_{24}$ - 24-hour creatinine excretion. SD - standard deviation. BMI - body mass index. For some patients not all data were available. 
This line is virtually identical to the line predicted from the theoretical model, representing accurate collections, for which the R factor is close to unity. The prediction line may be described by the situation of a beaker containing one liter of urine to which one litre of water is added: the volume doubles and the solute concentration halves. The line describes a common dilution situation, where the ratio of $c_{1}$ and $c_{2}$ is determined exclusively by the addition of water. We were greatly surprised to find this experimental evidence of such a simple situation in a complex biological environment like the kidney. This finding has several important implications. First, it is proof that a substantial number of patients are able to collect to near perfection. Second, the line permits the correction of faulty volumes to the volumes of a correct collection, provided that the ratio $c_{1} / c_{2}$ is correctly measured and remains constant over both collection days (for the calculations of volume corrections see Appendix 1).

\section{Case descriptions and corrections}

To illustrate the use of the model we have selected seven cases from daily routine (Table 2 and Figure 1).
Case 1. The $\Delta \mathrm{Cr}_{24}$ is amply below $4.0 \mathrm{mmol} /$ day so the patient has collected correctly. The relative difference between consecutive 24-hour urine volumes $(\Delta \mathrm{V} \%)$ is $-46 \%$, which is just normal (above $55 \%)$. The $\mathrm{R}$ factor is normal. The patient is found in sector N. Volume correction is not necessary.

Case 2. The patient has an increased $\Delta \mathrm{Cr}_{24}$ and a normal $\Delta \mathrm{V} \%$ and is found in sector $\mathrm{A}$. The patient has overcollected on the first day. The initial 24hour calcium excretions were 2.8 and 1.9 $\mathrm{mmol} / 24 \mathrm{~h}$ and were recalculated after volume correction to be 1.8 and $1.9 \mathrm{mmol} / 24 \mathrm{~h}$ respectively.

Case 3. In spite of the large difference between $\mathrm{V}_{1}$ and $V_{2}$, the creatinine concentrations are almost equal, which is illogical. The $\Delta \mathrm{Cr}_{24}$ is strongly increased. The patient has strongly undercollected on the second day, and is found in sector B. The initial 24-hour normetanephrine excretions were 21.2 and $8.1 \mathrm{mmol} / 24 \mathrm{~h}$ and were recalculated after correction of $\mathrm{V}_{2}$ to be 21.2 and $20.5 \mathrm{mmol} / 24 \mathrm{~h}$. The $\mathrm{R}$ factor is strongly increased.

Case 4. In spite of the large difference between $V_{1}$ and $V_{2}$, the patient has collected meticulously in view of the very low $\Delta \mathrm{Cr}_{24}$ and the $\mathrm{R}$ factor which is

TABLE 2. Examples of patient cases with incorrect collections

\begin{tabular}{|c|c|c|c|c|c|c|c|}
\hline Case & 1 & 2 & 3 & 4 & 5 & 6 & 7 \\
\hline Age (y) & 60 & 62 & 53 & 68 & 55 & 66 & 67 \\
\hline Gender & $\mathrm{F}$ & M & M & $\mathrm{F}$ & $\mathrm{F}$ & $\mathrm{F}$ & $\mathrm{F}$ \\
\hline $\mathrm{V}_{1}(\mathrm{~mL})$ & 772 & 2232 & 1980 & 1860 & 1874 & 1800 & 422 \\
\hline $\mathrm{V}_{2}(\mathrm{~mL})$ & 1232 & 2806 & 693 & 890 & 2392 & 3500 & 1400 \\
\hline $\mathrm{Cr}_{1}(\mathrm{mmol} / \mathrm{L})$ & 13.5 & 8.2 & 8.4 & 4.6 & 4.3 & 2.8 & 14.3 \\
\hline $\mathrm{Cr}_{2}(\mathrm{mmol} / \mathrm{L})$ & 7.6 & 4.2 & 9.6 & 9.5 & 6.4 & 2.8 & 4.4 \\
\hline $\mathrm{Cr}_{24-1}(\mathrm{mmol} / 24 \mathrm{~h})$ & 10.4 & 18.3 & 16.6 & 8.6 & 8.1 & 5.0 & 6.0 \\
\hline $\mathrm{Cr}_{24-2}(\mathrm{mmol} / 24 \mathrm{~h})$ & 9.4 & 11.8 & 6.7 & 8.5 & 15.3 & 9.8 & 6.2 \\
\hline$\Delta \mathrm{Cr}_{24}(\mathrm{mmol} / 24 \mathrm{~h})$ & 1.0 & 6.5 & 9.9 & 0.1 & -7.2 & -4.8 & -0.2 \\
\hline$\Delta \mathrm{V} \%$ & $-46 \%$ & $-23 \%$ & $96 \%$ & $71 \%$ & $-24 \%$ & $-64 \%$ & $-107 \%$ \\
\hline $\mathrm{R}$ & 1.11 & 1.55 & 2.48 & 1.01 & 0.53 & 0.51 & 0.97 \\
\hline Sector & $\mathrm{N}$ & A & B & $C$ & $E$ & $F$ & $\mathrm{G}$ \\
\hline
\end{tabular}

Suffix 1,2 - designation of the collection day. $\mathrm{V}$ - 24-hour volume. $\mathrm{Cr}$ - creatinine concentration. $\mathrm{Cr}_{24}$ - 24-hour creatinine excretion. $\Delta \mathrm{Cr}_{24}$ - difference between consecutive creatinine excretions. $\Delta \mathrm{V} \%$ - relative difference between consecutive 24-hour urine volumes. $\mathrm{R}$ - the ratio of $\mathrm{Cr}_{24-1} / \mathrm{Cr}_{24-2}$. Sector - position in the sectors as designated in Figure 1. 
almost equal to unity. The $\Delta \mathrm{V} \%$ is $71 \%$, which is above normal. The patient is found in sector $C$ and there is a slightly increased difference in water excretion. Volume correction is not necessary. Despite comparable urine volumes this patient contrast sharply with Case 3, where there is a gross collection error.

Case 5. The highest creatinine concentration is found in combination with the highest volume on day two, which is an illogical combination. The $\Delta \mathrm{Cr}_{24}$ is strongly decreased, as is the $\mathrm{R}$ factor. The patient is found in sector $E$. There has been an undercollection on the first day and an overcollection on the second day. The initial 24-hour calcium excretions were 7.1 and $13.3 \mathrm{mmol} / 24 \mathrm{~h}$ and were recalculated after volume corrections to be 9.6 and $9.5 \mathrm{mmol} / 24 \mathrm{~h}$ respectively.

Case 6. Despite a large difference in volume between $V_{1}$ and $V_{2}$, the creatinine concentrations are identical, which is illogical. The $\Delta \mathrm{Cr}_{24}$, the $\Delta \mathrm{V} \%$ and the $\mathrm{R}$ factor are all decreased. The patient is found in sector $\mathrm{F}$. The patient has grossly overcollected on the second day. The initial 24-hour metanephrine excretions were 0.25 and 0.52 $\mathrm{mmol} / 24 \mathrm{~h}$ and were recalculated after volume correction to be 0.25 and $0.27 \mathrm{mmol} / 24 \mathrm{~h}$ respectively. Likewise, the 24-hour sodium excretions were 58 and $126 \mathrm{mmol} / 24 \mathrm{~h}$ and were corrected to 58 and $64 \mathrm{mmol} / 24 \mathrm{~h}$ respectively.

Case 7. Despite a large difference in volume between $\mathrm{V}_{1}$ and $\mathrm{V}_{2}$, in view of the very low $\Delta \mathrm{Cr}_{24}$ and the $\mathrm{R}$ factor close to unity, the patient has collected meticulously. The $\Delta \mathrm{V} \%$ is largely decreased and the patient is found in sector $G$, indicating a large difference in the excretion of water. Volume correction is not necessary.

The cases presented above demonstrate the effectiveness of the model in solving discrepancies in the excretion of calcium, metanephrines, or cortisol (not shown). These corrections also demonstrate that there is only negligible influence from other interfering factors. We have implemented this authorisation in our daily routine practice. We have implemented an alert for incorrect collections in our laboratory information system. The clinical biochemist then decides to make a com- ment for the clinician and/or recalculate the results. We have also automated the correction calculations in an Excel program, which presents the classification sector, the $\mathrm{R}$ factor, the corrected volumes according to the different scenarios and optionally, the corrected 24-hour excretions of other solutes.

\section{Discussion}

As mentioned in the section Results we calculated the detection limits in patients as $\pm 4.0 \mathrm{mmol} / 24 \mathrm{~h}$ for the difference in creatinine excretion. These limits are similar to the early literature where critical differences in creatinine excretion were reported: $3.5 \mathrm{mmol} / 24 \mathrm{~h}$ for women and $4.3 \mathrm{mmol} / 24 \mathrm{~h}$ for men. However, these were calculated from a group of only 15 healthy individuals (10). More recently, in an elaborate study an optimal critical difference in creatinine excretion was defined as \pm $40 \%$ (11). When we apply this percentage to the mean creatinine excretion in our patient group (10.4 $\mathrm{mmol} / 24 \mathrm{~h})$ we obtain the same detection limits of $\pm 4.0 \mathrm{mmol} / 24 \mathrm{~h}$ for the difference in creatinine excretion. Limits for the difference in 24hour volume have been reported previously (9). These authors calculated a critical difference of $54.5 \%$ from a group of 459 healthy individuals. We adopted these limits as $\pm 55 \%$.

We studied the literature for the magnitude of factors influencing the creatinine excretion.

The effect of boiled meat on the urinary creatinine concentration has been documented: 0.7 $\mathrm{mmol} / 24 \mathrm{~h}$ increase $/ 100 \mathrm{~g}$ of boiled meat, and 1.5 $\mathrm{mmol} / 24 \mathrm{~h} / 100 \mathrm{~g}$ increase when compared to vegetarians $(12,13)$. These increases are too small to cause detection as an inappropriate collection by our method. The effect of creatine ingestion on the urinary creatinine excretion requires repeated ingestion of large doses of creatine ( $20 \mathrm{~g} /$ day): in such a regimen the urine creatinine excretion peaks at day five (to $5 \mathrm{mmol} / 24 \mathrm{~h}$ increase) and then stabilises at a lower increase of $2.8 \mathrm{mmol} / 24 \mathrm{~h}$ (14). Menstruation has been shown to have no influence on the creatinine excretion (15). The effect of strenuous exercise has been well documented: 30-50 km of walking during eight hours induced a 
mean increase of $3.5 \mathrm{mmol} / \mathrm{L}$ in creatinine excretion (16). Cycle ergometry until exhaustion caused a mean increase of $2.3 \mathrm{mmol} / 24 \mathrm{~h}$, range $0.2-4.2$ $\mathrm{mmol} / 24 \mathrm{~h}$ (17). When the exercise was moderate, others found only nonsignificant changes (18). Taken together it is highly unlikely that the factors mentioned above will lead to a false signal of urine collections as being inappropriate in our group of patients.

In some studies of urine collections, data of selfreported missed volumes have been published: a mean missed volume of $322 \mathrm{~mL}$ or $280 \mathrm{~mL}$ with a wide range of $20-735 \mathrm{~mL}(19,20)$. Likewise, when the literature is searched for reports of the urinary bladder volume, wide ranges are found: 120-465 $\mathrm{mL}, 15-750 \mathrm{~mL}$ (mean $322 \mathrm{~mL}$ for men, $255 \mathrm{~mL}$ for women) and 192-349 mL (25th-75th percentile, mean $246 \mathrm{~mL}$ in a large study of 1449 men) (21-23). It is conceivable that a patient mistakenly underor overcollects by one or even by two bladder volumes. If we assume a mean bladder volume of 300 $\mathrm{mL}$ and combine this with a mean patient creatinine concentration of $10 \mathrm{mmol} / \mathrm{L}$, the difference in excretion between two days of a missed portion is $3 \mathrm{mmol} / 24 \mathrm{~h}$ or even $6 \mathrm{mmol} / 24 \mathrm{~h}$. It is obvious that the effect of under- or overcollection by far outweighs the effect of the other factors. When we realised this we decided to develop a model based on the variation in creatinine excretion caused by under- or overcollection alone. Although we realise that this is an idealised situation, experience with the model in daily routine taught us that it proves very helpful to solve discrepancies in the interpretation of differences in excreted solutes.

There are a number of limitations in this study. The model rests on the assumption that under- or overcollection is dominant in the variability of the creatinine excretion. This may not always be the case with young healthy individuals instead of middle aged or elderly patients. The model will not detect under- or overcollection when it occurs in the same manner on both days. It also relies on accurately measured urine volumes and creatinine concentrations. In our hospital most of the collections are done consecutively. Therefore we chose to study this paired collections. Due to this practise in our hospital we had no data to study wheth- er the suggested delta check can be applied between two 24-hour urine collections several weeks apart. This would be interesting, although it would open the door to long term influences on the creatinine excretion, such as illness or medication changes.

The model must be used with caution in dialysis patients because these patients with advanced renal failure have artificial pathways of creatinine removal. We did not study the use of the model in paediatric populations.

Lastly, in one location of the hospital the urine weight is measured in grams, in the other location the volume is measured to the nearest $10 \mathrm{~mL}$. With an average excretion of $1000 \mathrm{~mL}$ the maximal error is $1 \%$ and can be neglected comparative to the large errors that we discuss.

There are also some strong points in this study. This is the first study with a standardised authorisation of duplicate 24-hour urine collections, which may be easily automated in the laboratory information system. It is one of the largest studies in the literature of duplicate urine collections. The model offers an approach to understand the effects of missed volumes on the excretion of other urine solutes and allows to correct for these effects. This minimises discrepancies and sharpens the interpretation. We also have presented evidence that patients are well able to collect to near perfection and that in this situation the urinary creatinine concentration is solely dependent on the amount of water excreted, which may vary up to a factor two between consecutive days.

The identification of volume errors as the major source of variation raises the question whether instructions for urine collection are always given and followed in a precise manner. This could be the subject of future research. We have shown that $22 \%$ of the patients is able to collect very accurately, that $56 \%$ of the patients collect with moderate precision and that $22 \%$ of the patients collect with highly unacceptable precision. The reader should realise that a critical difference of $\pm 4.0 \mathrm{mmol} / 24 \mathrm{~h}$ amounts to an approximate $40 \%$ in relative terms. In contrast, one fifth of our patients were able to collect within $\pm 0.5 \mathrm{mmol} / 24 \mathrm{~h}$ (approximately $5 \%$ ). 
Currently we do not know why these patients are able to collect to near perfection. Taken together these findings suggest that there is ample room for improvement. Apart from failing instructions, there could be other reasons for inadequate collections such as physical or psychiatrical limitations. This too could be the subject of further research.

In conclusion, the variability in creatinine excretion in our patient group is comparable to that of earlier studies (results not shown). Study of the literature identifies under- or overcollection as the major source of variability in creatinine excretion. We have developed a model for the authorisation of duplicate, consecutive 24-hour urine collections. This model is used in our hospital to detect, to interpret and to correct discrepant collections.

\section{References}

1. Wang Z-M, Gallagher D, Nelson ME, Matthew DE, Heymsfield SB. Total-body creatinine skeletal muscle mass: evaluation of 24-h urinary creatinine excretion by computerized axial tomography. Am J Clin Nutr. 1996;63:863-9. https:// doi.org/10.1093/ajcn/63.6.863

2. Stam SP, Eisenga MF, Gomes-Neto AW, van Londen $M$, de Meijer VE, van Beek $A P$, et al. Muscle mass determined from urinary creatinine excretion rate, and muscle performance in renal transplant recipients. J Cachexia Sarcopenia Muscle. 2019;10:621-9. https://doi.org/10.1002/jcsm.12399

3. Khan J, Bath K, Hafeez F, Kim G, Pesola GR. Creatinine Excretion as a Determinant of Accelerated Skeletal Muscle Loss with Critical IIlness. Turk J Anaesthesiol Reanim. 2018;46:311-5. https://doi.org/10.5152/TJAR.2018.60437

4. John KA, Cogswell ME, Campbell NR, Nowson CA, Legetic B, Hennis AJM, et al. Accuracy and Usefulness of Select Methods for Assessing Complete Collection of 24-Hour Urine: A Systematic Review Katherine. J Clin Hypertens. 2016;18:456-67. https://doi.org/10.1111/jch.12763

5. Cho MM, Yi M. Variability of daily creatinine excretion in healthy adults. Hum Nutr Clin Nutr. 1986;40:469-72.

6. Wulkan R, Horst van der M. [Gestandaardiseerde beoordeling van opeenvolgende 24-uurs urineverzamelingen]. Laboratoriumgeneeskunde. 2020;3:1-17. (in Dutch)

7. Carter CE, Gansevoort RT, Scheven L, Lambers Heerspink $H J$, Shlipak MG, de Jong PE, et al. Influence of urine creatinine on the relationship between the albumin-to-creatinine ratio and cardiovascular events. Clin J Am Soc Nephrol. 2012;7:595-603. https://doi.org/10.2215/CJN.09300911
We have demonstrated the effectivity of the model with examples from the daily practice. We have also provided the calculations in order to facilitate the reader in automation of the model. The results of this study may also be of use to laboratories that express the excretion of certain analytes as a ratio relative to creatinine, an approach that has been criticized $(24,25)$. We hope that our work will contribute to a revival of interest in the subject and will lead to further improvements in the accuracy of 24-hour urine collection.

\section{Acknowledgments}

We are indebted to dr M. van Borren for critically reading the manuscript.

\section{Potential conflict of interest}

None declared.

8. Raman A, Schoeller DA, Subar AF, Troiano RP, Schatzkin A, Harris $T$, et al. Water turnover in 458 American adults 4079 yr of age. Am J Physiol Ren Physiol. 2004;286:F394-401. https://doi.org/10.1152/ajprenal.00295.2003

9. Tormo C, Lumbreras B, Santos A, Romero L, Conca M. Strategies for improving the collection of 24-hour urine for analysis in the clinical laboratory: Redesigned instructions, opinion surveys, and application of reference change value to micturition. Arch Pathol Lab Med. 2009;133:1954-60.

10. Gowans EMS, Fraser CG. Biologial variation of serum and urine creatinine and creatinine clearance: $R a-$ mifications for interpretation of results and patient care. Ann Clin Biochem. 1988;25:259-63. https://doi. org/10.1177/000456328802500312

11. McGuire BB, Bhanji $Y$, Sharma V, Frainey BT, McClean $M$, Dong $C$, et al. Predicting Patients with Inadequate 24- or 48-Hour Urine Collections at Time of Metabolic Stone EvaIuation. J Endourol. 2015;29:730-5. https://doi.org/10.1089/ end.2014.0544

12. Mayersohn M, Conrad KA, Achari R. The influence of a cooked meat meal on creatinine plasma concentration and creatinine clearance. Br J Clin Pharmacol. 1983;15:227-30. https://doi.org/10.1111/j.1365-2125.1983.tb01490.x

13. Cross AJ, Major JM, Sinha R. Urinary biomarkers of meat consumption. Cancer Epidemiol Biomarkers Prev. 2011;20:1107-11. https://doi.org/10.1158/1055-9965.EPI11-0048

14. Hultman E, Söderlund K, Timmons JA, Cederblad G, Greenhaff PL. Muscle creatine loading in men. J Appl Physiol. 1996;81:232-7. https://doi.org/10.1152/jappl.1996.81.1.232 
15. Hall Moran V, Leathard HL, Coley J. Urinary hormone levels during the natural menstrual cycle: The effect of age. J Endocrinol. 2001;170:157-64. https://doi.org/10.1677/ joe.0.1700157

16. Bongers CCWG, Alsady M, Nijenhuis T, Tulp ADM, Eijsvogels TMH, Deen PMT, et al. Impact of acute versus prolonged exercise and dehydration on kidney function and injury. Physiol Rep. 2018;6:e13734. https://doi.org/10.14814/ phy2.13734

17. Bakońska-Pacoń E. Creatinine clearance and 24-hour creatinine excretion profile in the urine of people after physical exercises. Biol Sport. 2006;23:157-70.

18. Nemoseck T, Kern M. The effects high-impact and resistance exercise on urinary calcium excretion. Int J Sport Nutr Exerc Metab. 2009;19:162-71. https://doi.org/10.1123/ijsnem.19.2.162

19. Garde AH, Hansen ÅM, Kristiansen J, Ehlert Knudsen L. Comparison of Uncertainties Related to Standardization of Urine Samples with Volume and Creatinine Concentration. Ann Occup Hyg. 2004;48:171-9.

20. Harris SA, Purdham JT, Corey PN, Sass-Kortsak AM. An evaluation of 24-hour urinary creatinine excretion for use in identification of incomplete urine collections and adjustment of absorbed dose of pesticides. AlHAJ. 2000;61:649-57. https://doi.org/10.1202/0002-8894(2000)061<0649:AEOUC E>2.0.CO;2
21. Dicuio M, Pomara G, Menchini Fabris F, Ales V, Dahlstrand C, Morelli G. Measurements of urinary bladder volume: Comparison of five ultrasound calculation methods in volunteers. Arch Ital Urol Androl. 2005;77:60-2.

22. Esteves FP, Taylor A, Manatunga A, Folks RD, Krishnan M, Garcia E V. 99mTc-MAG3 renography: normal values for MAG3 clearance and curve parameters, excretory parameters, and residual urine volume. AJR Am J Roentgenol. 2006;187: W610-7. https://doi.org/10.2214/AJR.05.1550

23. Blanker $M H$, Groeneveld FPMJ, Bohnen AM, Bernsen RMD, Prins A, Thomas S, et al. Voided volumes: Normal values and relation to lower urinary tract symptoms in elderly men, a community-based study. Urology. 2001;57:1093-8. https:// doi.org/10.1016/S0090-4295(01)00988-8

24. Boeniger MF, Lowry LK, Rosenberg J. Interpretation of Urine Results Used to Asses Chemical Exposure with Emphasis on Creatinine Adjustments: A Review. Am Ind Hyg Assoc J. 1993;54:615-27. https://doi. org/10.1080/15298669391355134

25. Jones AN, Shafer MM, Keuler NS, Crone EM, Hansen KE. Fasting and postprandial spot urine calcium-to-creatinine ratios do not detect hypercalciuria. Osteoporos Int. 2012;23:553-62. https://doi.org/10.1007/s00198-011-1580-7 


\section{Appendix 1. Calculation of the volume corrections}

The mathematically corrected 24-hour volumes $V_{1 c}$ and $V_{2 c}$ must lie on the curve $y=1 / x$.

\section{Correction of $\mathrm{V}_{1}$ only (scenarios 1 and 4)}

$c_{1} / c_{2}=1 /\left(V_{1 c} / V_{2}\right)$ or $V_{1 c} / V_{2}=c_{2} / c_{1}$.

When $V_{1}$ is too large, the correction volume $z$ has to be subtracted:

$\mathrm{V}_{1 \mathrm{c}}=\mathrm{V}_{1}-\mathrm{z}$;

$\left(\mathrm{V}_{1}-\mathrm{z}\right) / \mathrm{V}_{2}=\mathrm{c}_{2} / \mathrm{c}_{1}$.

From this follows:

$\mathrm{z}=\mathrm{V}_{1}-\left(\mathrm{V}_{2} \times \mathrm{C}_{2} / \mathrm{c}_{1}\right)$ and

$\mathrm{V}_{1 \mathrm{c}}=\mathrm{V}_{2} \times \mathrm{c}_{2} / \mathrm{c}_{1}$.

\section{Correction of $\mathrm{V}_{\mathbf{2}}$ only (scenarios $\mathbf{2}$ and $\mathbf{5}$ )}

$c_{1} / c_{2}=1 /\left(V_{1} / V_{2 c}\right)$ or $V_{1} / V_{2 c}=c_{2} / c_{1}$.

When $V_{2}$ is too small, $z$ has to be added:

$\mathrm{V}_{2 \mathrm{c}}=\mathrm{V}_{2}+\mathrm{z}$;

$\mathrm{V}_{1} /\left(\mathrm{V}_{2}+\mathrm{z}\right) /=\mathrm{c}_{2} / \mathrm{c}_{1}$.

From this follows:

$\mathrm{z}=\left(\mathrm{V}_{1} \times \mathrm{c}_{1} / \mathrm{c}_{2}\right)-\mathrm{V}_{2}$ and

$\mathrm{V}_{2 \mathrm{c}}=\mathrm{V}_{1} \times \mathrm{c}_{1} / \mathrm{c}_{2}$.

\section{Correction of both $V_{1}$ and $V_{2}$ (scenarios 3 and 6 )}

$\mathrm{c}_{1} / \mathrm{c}_{2}=1 /\left(\mathrm{V}_{1 \mathrm{c}} / \mathrm{V}_{2 \mathrm{c}}\right)$ or $\mathrm{V}_{1 \mathrm{c}} / \mathrm{V}_{2 \mathrm{c}}=\mathrm{c}_{2} / \mathrm{c}_{1}$.

When $V_{1}$ is too small and $V_{2}$ is too large, both volumes have to be corrected:

$\left(\mathrm{V}_{1}+\mathrm{z}\right) /\left(\mathrm{V}_{2}-\mathrm{z}\right)=\mathrm{c}_{2} / \mathrm{c}_{1}$

$\left(V_{1} \times c_{1}\right)+\left(z \times c_{1}\right)=\left(V_{2} \times c_{2}\right)-\left(z \times c_{2}\right)$

$z\left(c_{1}+c_{2}\right)=\left(V_{2} \times c_{2}\right)-\left(V_{1} \times c_{1}\right)$

$\mathrm{z}=\left[\left(\mathrm{V}_{2} \times \mathrm{c}_{2}\right)-\left(\mathrm{V}_{1} \times \mathrm{c}_{1}\right)\right] /\left(\mathrm{c}_{1}+\mathrm{c}_{2}\right)$.

In the inverse situation, the correction volume $z$ changes sign. When $V_{1}$ is too large and $V_{2}$ is too small, both volumes have to be corrected:

$\left(\mathrm{V}_{1}-\mathrm{z}\right) /\left(\mathrm{V}_{2}+\mathrm{z}\right)=\mathrm{c}_{2} / \mathrm{c}_{1}$

$\left(V_{1} \times c_{1}\right)-\left(z \times c_{1}\right)=\left(V_{2} \times c_{2}\right)+\left(z \times c_{2}\right)$

$z\left(c_{1}+c_{2}\right)=\left(V_{1} \times c_{1}\right)-\left(V_{2} \times c_{2}\right)$

$\mathrm{z}=\left[\left(\mathrm{V}_{1} \times \mathrm{c}_{1}\right)-\left(\mathrm{V}_{2} \times \mathrm{c}_{2}\right)\right] /\left(\mathrm{c}_{1}+\mathrm{c}_{2}\right)=-\left[\left(\mathrm{V}_{2} \times \mathrm{c}_{2}\right)-\left(\mathrm{V}_{1} \times \mathrm{c}_{1}\right)\right] /\left(\mathrm{c}_{1}+\mathrm{c}_{2}\right)$. 